\title{
Law, Learning, Technology: Reiving Ower the Borders
}

\author{
Dr Paul Maharg \\ University of Strathclyde
}

\begin{abstract}
Serious consideration of our students' learning requires us to engage with the theoretical constructs of other disciplines, some of which have much to tell us about how we teach law, how we might teach it more effectively; how our students learn and what they understand as learning. This interdisciplinary understanding is an essential component in the dialectic between theory and praxis of teaching and learning, and the law. If this is true for what might be termed more traditional learning methods, it is even more the case for computer-based educational interventions. In computer-based learning, the management of learning on many levels becomes critical to educational success, and the understanding and application of interdisciplinary theory plays an important role in the design and development of materials and in the learning events themselves.
\end{abstract}

\section{Introduction}

More and more within universities there is a call for academics to develop an awareness of the educational practice within their discipline. All the recent major reports on higher education make mention of the necessity for disciplines to examine their teaching and learning, and to consider how it might be carried out more effectively. Dearing, Garrick, and Booth for instance all point to this reflexive self-awareness as a necessary component in the improvement of student learning. Thus Booth, in his statement of the professional values underpinning practice, talked of the importance of 'a commitment to continued reflection and consequent improvements to practice'. ' Later in the report, Booth notes that one of the aspects of the HE teacher's role and expertise that was acknowledged as requiring 'greater emphasis' was

[a]n understanding of the relationship between the research and teaching processes. The ability to engage in critical enquiry, to interpret, to evaluate, and an understanding of how to develop these intellectual abilities in students. Allied to this, the need for constant reflection on and effective evaluation of one's own teaching methods and practice. ${ }^{2}$

\footnotetext{
${ }^{1}$ Accreditation and Teaching in Higher Education, Final Report, May 1998, para. 2.7

2 Ibid, 'Questions for Consultation', d.3.2. The link between teaching and research indicated by Booth deserves much greater research attention than it has hitherto attracted. There is evidence which points to the effect that an over-emphasis on research activity has upon the quality of attention given by the profession to teaching and learning See for example J. Court, Opportunity Blocks : A Survey of Appointments and Promotion in UK Higher Education, London, AUT, 1998 and L. Elton, 'Effect of
} 
Such reflection inevitably leads us to consider the wider view beyond our individual disciplines. As anyone who has asked students to undertake reflective analysis knows, self-reflection inevitably involves an awareness of context, both social and intellectual, and is a product of the interaction of both. ${ }^{3}$ This is as true of teaching as it is of learning in higher education, discussion of which immediately involves us in two disciplines: education and the knowledge domain within which teaching takes place. But this is only the start. Disciplines break down into sub-disciplines, which frequently overlap with each other and other disciplinary domains. Within the cultures and activities of these domains, there is a wealth of teaching and learning experience which one can develop in one's own discipline. John Cowan has highlighted this recently:

It is a singularly British characteristic to tie staff and curriculum development firmly to discipline areas. ... I have often found that good teaching approaches which I have encountered in other discipline areas can readily be translated into a form suitable for use by me and my students -- with less demand on my ingenuity and time than if I had needed to invent something from scratch. ${ }^{4}$

Interdisciplinary comparison is therefore valuable to the process of reflection on what our teaching and our students' learning activities are, what they achieve and how they can be improved. Indeed, I would argue that, in sub-areas such as IT and Law, it is impossible not to be interdisciplinary, and that greater interdisciplinarity is essential to the design and implementation of learning materials in cyberspace. In order to explore this argument, I shall take two examples. First I shall examine the application of aspects of the considerable literature of composition and rhetorical theory on legal writing, and analyse a practical implementation of this in CBL courseware. Secondly, I shall analyse the use to which Toulmin's model of argumentation is put in some of the AI literature on the teaching and learning of argument skills in law.

\section{Splicing rhetoric and legal writing into the curriculum: generic issues}

The nature of the traditional culture and design of the legal curriculum gives rise to two structural and related difficulties for the teaching of writing and argument skills. The first is the well-documented tendency for law teachers to focus on the teaching and learning of substantive law, rather than legal skills or the integration of skills and knowledge. The second involves the embedding of argument and writing skills throughout the curriculum. While writing and argument skills can be given priority in specific courses, such courses become 'ghettos' for skills development unless these skills

Funding Council Policies on Teaching Quality', Research, Teaching and Learning in Higher Education, B. Smith and S. Brown, (eds), London, Kogan Page, 1995 pp.40-48

${ }^{3}$ See for example J. Cowan, On Becoming an Innovative University Teacher: Reflection in Action, London, Society for Research into Higher Education and Open University Press, 1998, p.18

${ }^{4}$ Ibid, p. 121 
are distributed in teaching, learning and assessment activities throughout the curriculum. If there is no distribution, then transfer of learning between predominantly skills-based classes and predominantly knowledge-based classes becomes more difficult to achieve, because boundaries between skills learning and law learning are actually reinforced by the presence of skills-based classes.

In addition to these curricular issues, there are a number of generic issues in the teaching and learning of writing and argument itself, which require to be addressed. These are issues which surface in the cognitive literature in the form of apparent dualisms: individual $v$. disciplinary forms of writing and argument; process of writing $v$. product of text and argument; generic theory of argumentation $v$. specific and discipline-based implementations in educational and professional practice. Any approach to argumentation requires to deal with these tensions, and for this reason I shall outline their consequences in more detail below.

\section{Individual $v$ disciplinary forms of argument}

Broadly speaking, this concerns the distinction between writing as expression of individual voice, and writing as a disciplinary or paradigmatic exercise (the Foucaultian echo is deliberate). If students are learning a disciplinary skill, what part does selfexpression play in this? This question, present in the composition literature for some time, was the subject of a dialogue between Peter Elbow and David Bartholomae. ${ }^{5}$ Bartholomae emphasised the responsibility of academics within a discipline to explicate text forms important within to the contemporary discipline, and to induct students into their use within the academy:

[i]nside this linguistic present, students (with instruction -- more precisely, with lessons in critical reading) can learn to feel and see their position inside a text they did not invent and can never, at least completely, control. Inside a practice: linguistic, rhetorical, cultural, historical. ${ }^{6}$

Elbow, on the contrary, has a much more informal concept of the purpose of writing. He views the academic essay, for example, as a narrative, which expresses personal point of view and is a process of the discovery of self-confidence and personal voice. It is through the development of this, Elbow asserts, that students begin the journey from the periphery of a discipline to its centre.

In the dialogue between Elbow and Bartholomae are two fundamentally opposing views of how students may be inducted into the argument structures of a discipline, one emphasising individuality, self-expression, the discovery of meaning through the discovery of voice, while the other talks in terms of the role of the institution, paradigmatic models and the formal markers of what constitutes good disciplinary texts. ${ }^{7}$

\footnotetext{
${ }^{5}$ D. Bartholomae 'Writing with teachers: a conversation with Peter Elbow' College Composition and Communication 46, 62-71, 1995a; Bartholomae, D., et. al. 'Interchanges: responses to Bartholomae and Elbow' College Composition and Communication 46, 84-107, 1995b

${ }^{6}$ Ibid., Bartholomae, 1995a, p.65

${ }^{7}$ Sharples and Pemberton have characterised these positions as different strategies within the writing process: either 'following a thread' (writing as discovery) or 'filling a template' (writing based on 'already written texts as a guide to planning'). See M. Sharples, and L. Pemberton, 'Representing writing: external representations and the writing process', in P. Holt, and N. Williams, (eds), Writing: State of the Art,
} 
Bartholomae and Elbow thus represent two established positions within the research literature on composition and writing research. Recently, however, some researchers have identified the need to 'blur the distinction' between these two quite different approaches, so that teaching practice can take account of both positions. ${ }^{8}$

Within a university setting the same tension of opposites is present. Individual writers must write and carry out private cognitive processes; but they must do so within a discourse community, an interpretive community, as Bartholomae, Fish, Bizzell, Charney $\&$ Carlson and others have pointed out. ${ }^{9}$ Their work, and the research of many others, highlights the extent to which legal genres, both professional and academic, are not merely part of socially constructed reality: they are socially constructive of the law and lawyers' professionalism. ${ }^{10}$ Moreover, the tension between private writing and argument and discourse communities is complicated in legal curricula by the presences of two sets of discourse genres -- the academic and the professional. Students require to use, and write within, genres of academic writing and reading, but they also need to interact with the texts and pragmatic understandings of the professional discourse community, which are created by professionals outside the university, but often used within it in the form of cases, statutes and practitioner texts. ${ }^{11}$ The relationship between academic and the professional genres of argument, though seldom the subject of overt instruction, thus require to be negotiated by students in their learning of legal genres.

\section{Process of writing $v$ text product}

The tension between process and product is another generic issue in the teaching and learning of argument and writing. Scardamalia and Bereiter, for example, have highlighted the importance of process-oriented interventions in their differentiation between substantive and procedural facilitation in writing. ${ }^{12}$ Their analysis applies to the domain of legal argument: the argumentational skills that students learn in the domain of law cannot be developed separately from the process of reading others' texts, or

\footnotetext{
Oxford, Intellect, 319-36, 1992, 325

${ }^{8}$ M. Lea, 'Academic literacies and learning in higher education: constructing knowledge through texts and experience', Studies in the Education of Adults, Oct 1998, 30, 2, 156-65, p.157

${ }^{9}$ D. Bartholomae 'Inventing the university', in M. Rose, (ed) When a Writer Can't Write: Studies in Writer's Block and Other Composing Process Problems, New York, Guildford Press, 1985; S. Fish, Doing What Comes Naturally: Change, Rhetoric and the Practice of Theory in Literary and Legal Studies, Oxford, Clarendon Press, 1989; P. Bizzell, P., 'Cognition, convention, and certainty: what we need to know about writing', Pre/Text, 3, 213-43, 1992; D. Charney \& R. Carlson, 'Learning to write in a genre: what student writers take from model texts', Research on the Teaching of English, 1995, 29, 1, 88-125

${ }^{10}$ For examples of this social construction see P. Goodrich, Legal Discourse: Studies in Linguistics, Rhetoric and Legal Analysis, London, Macmillan, 1987; G. Kress, and T. Threadgold, 'Towards a social theory of genre', Southern Review, 21, 215-43, 1988; C. Bazerman, and J. Paradis, Textual Dynamics and the Professions: Historical and Contemporary Writing in Professional Communities, Madison, Wisconsin, University of Wisconsin Press, 1991

${ }^{11}$ For discussions of the relationships between academic and professional learning, see for example See for example M. Eraut, Developing Professional Knowledge and Competence, London, Falmer Press, $1994 ;$ P. Birks, 'The Academic and Practitioner', Legal Studies, 18, 4, 397-414, 1998, 410-11; P.C. Kissam, 'Thinking (by writing) about legal writing', Vanderbilt Law Review, 40, 135-73, 1987, 142

${ }^{12}$ M. Scardamalia and C. Bereiter, 'From conversation to composition: the role of instruction in a developmental process', in Glaser, R., editor, (1986) Advances in Instructional Psychology, vol 2, Hillsdale NJ: Lawrence Erlbaum Associates, 1982, 52
} 
producing a text which embodies their own arguments. Yet while in all undergraduate programmes the product of law is examined (legislation, case reports, judgements, affidavits and the like), the process by which the linguistic artefacts are produced is probably less often presented to students as problematic; and when it is made overt, it is so normally as part of a course in legal system, Jurisprudence or critical theory. Thus legal semioticians such as Bernard Jackson deploy in the legal domain cognitive research into composition and sociolinguistics as well as the semiotics of legal language; but it is probably true to say that his texts rarely if ever find their way into courses on which students learn the skills of legal writing and argument. ${ }^{13}$

There are many reasons why legal writing is not problematized, most of which stem from the nature of the culture of legal education and the forms of inquiry and argument it privileges. ${ }^{14}$ In the USA, for example, many authors report the low status of legal writing courses. ${ }^{15}$ But part of the problem lies with the innovations that these courses sometimes introduce into the curriculum. When the focus is moved from culturally traditional methods of teaching and learning the product of law to teaching the process of learning the discipline of law this may be resisted by staff for whom the research into composition and argument is recondite, and viewed as lying beyond the domain of the discipline.

\section{Writing theory: generic rules $v$ specific practices}

If the claims of process and product require to be balanced within the curriculum, there is a similar tension between the claims of generic theory in argument and writing, and the specific forms of argument and writing perceived by a discourse community as essential to its educational and professional contexts. Whether or not generic theories of argumentation such as Toulmin's may provide an adequate description of forms of legal argumentation (and we shall examine this in detail later in the paper), it is another matter as to whether or not such descriptive tools can support students in their assessment of the quality of disciplinary argument, as well as their modelling and recreation of that 'local knowledge' within the discipline. ${ }^{16}$ The same may well be true with reference to writing -- for example the concept of 'generic structure potential', ${ }^{17}$ or 'schematic structure"18 -but arguably it is more difficult to assess the pedagogic value of these essentially descriptive categories.

All of these issues bear directly on the student experience of learning particular forms of

\footnotetext{
${ }^{13}$ B. Jackson, Making Sense in Law: Linguistic, Psychological and Semiotic Perspectives Legal Semiotics Monographs, Liverpool: Deborah Charles Publications, 1995

${ }^{14}$ Within the last decade this has been the subject of considerable critique. See for example M.J. Le Brun and R. Johnstone, The Quiet (R)evolution: Improving Student Learning in Law , North Ryde, New South Wales, The Law Book Company Limited, 1994; C. Maughan and J. Webb, Lawyering Skills and the Legal Process, London, Butterworths, 1995; C. Maughan and J. Webb, (eds) Teaching Lawyers'Skills, London, Butterworths, 1996

${ }^{15}$ For a brief summary of this, see P. Maharg, 'Contracts: An Introduction to the Skills of Legal Writing and Analysis', <http://elj.warwick.ac.uk/jilt/cal/1maharg/default.htm>, 1996

${ }^{16}$ C. Geertz, Local Knowledge New York, Basic Books, 1983

${ }^{17}$ R. Hasan, 'The structure of a text', in M.A.K Halliday and R. Hasan (eds), Language, Context and Text: Aspects of Language in a Social-Semiotic Perspective, Oxford, Oxford University Press, 1989

${ }_{18}$ J.R. Martin, Factual Writing: Exploring and Challenging Social Reality Oxford: Oxford University Press, 1989
} 
argument and writing within a professional discipline. The claim of each item within the contrasting pairs above is a valid one, but each item requires to be balanced not only within its own dyad, but within the dialogue of other dyads, other issues and many other competing claims to priority within the curriculum and within the profession. In this respect, the resolution of each pair involves a consideration of all: if educational interventions into argument and writing are to be effective, they require integrative strategies which are underpinned by researched and appropriate educational theory, and designed for local programmes of study. The literature of curriculum design and cognitive research supports such an approach. ${ }^{19}$

\section{Contracts: A case study in interdisciplinary IT}

We can see one attempt to resolve the competing demands of the dyads outlined above in a legal writing program, Contracts, which was based on interdisciplinary research in rhetoric, law and CAL. ${ }^{20}$ Based on earlier work carried out with literature students, it seemed possible that support for the writing and problem-solving process could be offered to students through the medium of hypertext tutorials. ${ }^{21}$

I began to sketch out a series of tutorials based on the models of writing research proposed by Flower and Hayes, and as amended by Scardamalia, Bereiter, Sharples and others, and designed specifically for the needs of first year law students studying Obligations at Glasgow University. Two problems presented themselves from the start. The first was rhetorical, and faced by most writing instructors, namely the paradox created by adopting the Flower and Hayes models: if writing is not a prescriptive stage process (think $>$ plan $>$ write), but a matter of, inter alia, juggling constraints, how may we teach writing skills successfully? If we take a linear path through writing activities such as note-taking, planning, first drafts, revisions, final drafts, then this would emphasise the stage model which Flower and Hayes have argued against in their research. But if we are to give guidance in writing skills, there must be some order, taxis, imposed upon the writing process, which, with its intractable simultaneity of mental processes, is highly resistant to analysis. This paradox can never really be solved by writing teachers, but hypertext software does significantly reduce the problem. Students could be given the freedom to explore the program in any order: if they wanted to work on revision strategies, for instance, they could do so without working through sessions on planning or first drafts. Similarly, they needn't complete all the activities within a tutorial or session, only those they felt were relevant to their needs or necessary to their understanding of the strategy.

\footnotetext{
${ }^{19}$ L. Flower L. and J. Hayes 'Cognition, context, and theory building.' College Composition and Communication. 40: 282-311, 1989; M. Eraut, op.cit; R. Barnett The Limits of Competence: Knowledge, Higher Education, and Society Philadelphia, Society for Research into Higher Education and Open University Press, 1994

${ }^{20}$ See Maharg, op.cit 1996

${ }^{21}$ P. Maharg, 'WriteGuide and ReportGuide: Hypertext Writing Programs', Proceedings of the STELLA Symposium: Computers in Teaching and Research in English University of Glasgow, 1991
} 
The second problem was a larger one. To call what appears on a computer screen a 'tutorial' is really to use a transferred epithet, for these tutorials could not be representations on screen of real tutorials. In what sense, therefore, were the divisions of activities and text on screen tutorials? The question raised another problem, that of defining the identity of real tutorials. 'Tutorial' is a notoriously vague word, and much of the activity, which goes on in it, depends on the role taken by the tutor. Baumgart identified six distinct roles adopted by tutors - data input, cognitive engineer, elaborator, stage setter, probe and reflexive judge. ${ }^{22}$ The latter two roles alone, according to Baumgart, led to increase in the quality of discussion: 'rather than give answers or solutions to questions or problems', the probing tutor tended to redirect these to the students, 'often with hints or clues to direct thinking'. The reflexive judge was characterised by 'frequent talk and frequent reacting' where the tutor's evaluations were 'both supportive and corrective'. ${ }^{23}$

Now one of the striking features of almost any discussion with students about writing is how little time is given over to discussion of the writing process, as opposed to the end product, which can frequently be the object of considerable criticism. This is the result of socialisation in teaching and assessment, which directs students' attention to some processes but not others. If little advice is given to students on how to write better essays, reports, assignments, while copious comment is given to the substantive subject of the writing then, vis-à-vis writing, tutors probably tend to adopt the roles of data input, elaborator or at most, stage setter (eg giving essay specifications, without exploring with students how the final product may be achieved). As a result, discussions with students about their writing will tend to be descriptive of process, rather than analytical. One reason for this could be the lack on the students' part of tools with which to analyse their writing strategies and consider alternatives. The tutorials or sessions aimed to give students the tools to reflect upon their writing themselves, and to create a supportive environment where students could contrast their own with an expert legal essay and each other's drafts.

The program aimed to create an exploratory learning environment, therefore, in which students could learn about writing processes and practise alternative strategies. The program would thus mimic as far as possible the writing tutorial, in which a piece of writing is analysed and discussed, and students put into practice in small-scale activities the metacognitive skills discussed in the tutorial. But if this were to be the case, it would be impossible for the computer to analyse the students' writing, as would a tutor. The role of computer as reflexive judge would seem to be automatically eliminated as a role model. At first glance this would appear to be a severe shortcoming of the program. Interactivity - Baumgart's 'frequent talk and frequent reacting' - has come to be seen as the benchmark of innovative software, and is frequently approved as the ideal role a computer can play - interactive writing assistants, partners, workbenches, environments (there are many such metaphors, but all stress interactivity) are typical examples.

\footnotetext{
${ }^{22}$ N.L. Baumgart, 'Verbal Interaction in University Tutorials', Higher Education, 5, 301-317, 1976. For an example of this type of analysis in a medical setting, see M.L. Thomas, D. Snadden \& S. Carlisle, "When the talking starts": a framework for analysing tutorials', Medical Education, 1998, 32, 502-06

${ }^{23}$ Ibid., 312-13
} 
Yet it may be that the role of computer as reflexive judge is a flawed metaphor. The basis of the reflexive judge role, as of all tutor roles, is based on entirely open communication, and on premise that, however limited the communication may be in practice, the opportunity exists for the tutorial's discussion to be open-ended. Interactive software may appear to be a tutor, but it cannot, for the moment at least, match the real tutor for flexibility of response, depth of expertise, sensitivity of response to the physical presence of a student, and perception of the links between a student's personality and his/her work. In the end, Baumgart's 'frequent talk and frequent reacting' is not sufficient: there has to be more sophistication of response. After all, quality interaction is concerned less with quantity, and more with showing students how they might use strategies to become more perceptive self-critics. In this sense, a virtual tutorial could be acceptable as one of a range of heuristics, which could be created to support student writing. Nowhere is this more important than in the area of writing skills, which is pre-eminently a practical activity. No one ever learned writing as a direct result of being taught it; they learned through their interpretive experience of praxis and because they wrote within a discourse community whose rules they learned through reading, modelling templates, finding a voice, and through the comment and criticism of others.

But before I considered a computer program there were a number of considerations to balance, most of them interdisciplinary, and more or less summed up by two questions: 1. why might a computer be a more efficient medium than paper for this learning tool?

2. how would the computer environment affect the learning objectives and structure of my text?

These questions were fairly fundamental and required more than an acknowledgement of their existence, and an awareness of possible answers to them before attempting to design an electronic learning environment.

The first one was the most difficult to answer, in part because it is impossible, in advance of the system being constructed, to say what students would have wanted from it. The number of variables affecting the answer are considerable, too - form of text, domain knowledge of the text and the knowledge structure implicit in it, task analyses storyboarding, models of students' prior learning, and so on. The research literature can only give guidance and analogies here, not a complete answer. Nevertheless, this body of research was invaluable, for it discussed models and exemplars of hypertext representation which could be adapted to the specific remit I had. Nielsen, for example, asked a group of computer science students to state their preferences, whether online or in printed format, for reading three types of text: computer manuals, student textbooks and fiction. ${ }^{24}$ The online preference was sub-divided into one with user annotations, in the form of hypertext, and plain online text without such annotation facilities. The results showed that, given the user annotation facility, students approved of online manuals, viewed textbooks as having small disadvantages online, and much preferred their fiction printed. Regarding the two types of online forms - with or without user annotation

\footnotetext{
${ }^{24}$ J. Neilsen, 'Online documentation and reader annotation', in Proceedings of the 1st Conference on Work with Display Units, 526-9, Stockholm, Sweden, 1986
} 
facilities - students viewed annotation a considerable advantage for online textbooks, a small advantage for online manuals and no advantage for their online fiction.

At first glance these results are not a resounding affirmative in favour of an online writing program. But again, if one analyses the context of the questionnaire, the results become more equivocal. The nature of the text, the human-computer interfaces and the model of the user have bearing on the result. For example, what sort of textbook are we talking about here? As linguistics research has shown for some time now, texts which appear to have an apparently linear structure often have rich relational structures and adjacencies. ${ }^{25}$ How was the electronic textbook presented on-screen? How were the hypertext links designed? Was the user engrossed by the progam, and was it pleasurable to use? What was the user expected to be able to do at the start of the program? at the end? and so on. As Nielsen has pointed out, 'users are not necessarily good designers'. What the literature did point to, though was the conclusion, controversial in some articles, but increasingly accepted by a range of theorists and practitioners, that 'hypermedia systems should be viewed not principally as teaching tools, but rather as learning tools'. ${ }^{26}$

If the first of the two questions listed above was unanswerable until the program was constructed, the second bore directly on the construction of the program, and required very definite answers. But here as everywhere in the field of hypermedia, nothing can be taken for granted. Every assumption must be examined to ensure its fit to the immediate context of learning. In particular, the advice given by most people who have worked with hypertext, namely that structuring the hypertext before constructing it is essential, turned out to be a more complex issue than it appeared. At first glance the advice seemed eminently practical. As George Landow pointed out, 'hypertext's intrinsic openendedness removes both the need to create some final universalizing approach to arranging data or event the possibility that one can do so at all' ${ }^{27}$ However, to take

\footnotetext{
${ }^{25}$ See, for example, D. Schiffrin, Approaches to Discourse, Oxford, Blackwell, 1994; and Robert de Beaugrande, Text, Discourse and Process: Towards a Multidisciplinary Science of Texts Norwood, NJ: Ablex, 1980

${ }^{26}$ P.C. Duchastel, 'Discussion: Formal and Informal Learning with Hypertext', Designing Hypermedia for Learning, Proceedings of the NATO Advanced Research Workshop on Designing Hypertext/Hypermedia for Learning, Rottenburg/Neckar, FRG, July 1989, D.H. Jonassen and H. Mandl (eds),Berlin, SpringerVerlag, 135-43, 1989. In the same volume, Mayes, Kibby and Anderson, quoting Frisse, raised the interesting issue of conceptual design, of hypertext and its effect on the user:

Frisse has discussed how the way in which a hypertext system is conceptualized affects its design. If a hypertext node is seen as relatively autonomous then retrieving its information will involve the 'small-document' approach. If on the other hand the semantic links between nodes are emphasised then retrieving information will be seen as similar to traversing a directed graph. The smalldocument approach emphasises pattern matching; the graph-traversal approach emphasizes browsing.

T. Mayes, M. Kibby and T. Anderson, 'Learning About Learning from Hypertext', ibid, pp.231-2, quoting M.D. Frisse, 'Searching for information in a hypertext medical handbook', Hypertext '87, eds J.B. Smith, F. Halasz, N. Yankelovich, M. Schwartz, and F. Weiss, Chapel Hill: University of North Carolina, 1987, pp.175-188.

${ }^{27}$ G. Landow, 'Popular Fallacies About Hypertext', Designing Hypermedia for Learning, Proceedings of the NATO Advanced Research Workshop on Designing Hypertext/Hypermedia for Learning, Rottenburg/Neckar, FRG, July 1989, D.H. Jonassen and H. Mandl (eds),Berlin, Springer-Verlag, 135-43, 1989,46
} 
Landow's observation a step further, it is easy to create a structure in advance of implementation, but extremely difficult to foresee how each node of the hypertext will affect every other node. One can really only appreciate the effect of moving from node to node through the hypertext by actually constructing it and doing it one's self. Storyboarding and preview overmaps can only give a restricted sense of a reader's experience of the text and the relationship between one textual node and another, both in the navigational and rhetorical senses. Perhaps the nearest analogy one can draw is between the design of a building by an architect, and its actual construction. The first is an indispensable tool for architects, surveyors, builders, and for the communication of technical data to others; but it can hardly be said to give the end-user of the building the experience of walking through and living in the constructed and finished spaces.

The construction of the program therefore required constant and interdisciplinary attention to be given to the educational aims, the research literature in rhetoric, law and HCI, and in local solutions based upon a profile of the typical user, the type and structure of information. Thus as far as the rhetorical research was concerned, generic rules of writing were embedded and adapted to specific practices of legal argumentation, not merely in the area of Scots law, but in Scots legal argumentation as it was taught in the context of the Obligations course at Glasgow University. Writing products were broken down into hypertext units to illustrate process, and to focus students' attention on their own writing procedures. The program communicated the rules by which writing products were judged by examiners, and demonstrated how these rules operated in practice. It illustrated and encouraged personal voice and paradigm forms of argument, as the following samples from the qualitative feedback we obtained from students shows:

[Contracts] helped me structure my work. Helped illustrate the level of detail expected and how to present a full, balance answer.

Gave me a better knowledge of how to write or improve an essay in Contracts, ie the logical progression through a law problem-type essay.

Writing skills advice - brilliant - no training given on how to write a law essay so this is very helpful. Sample essays and commentaries are also very useful. ${ }^{28}$

In this example, interdisciplinary research into HCI, rhetoric, legal analysis, and compositional studies was called upon in the creation of the program. Indeed, integration of models and approaches from these domains within the program was essential to its implementation. ${ }^{29}$ Such integration, I would argue, is essential also to other crossdisciplinary initiatives involving law and IT, particularly in the field of AI.

\footnotetext{
${ }^{28}$ Feedback obtained from students in action research to determine the effectiveness of the program, conducted at Glasgow University in 1994

${ }^{29}$ For other examples of such interdisciplinary research, see P. Maharg, '(Re)-telling stories: narrative theory and the practice of client counselling', The Law Teacher, 1996, 30, 3, 295-314; K. Barton, P. McKellar \& P.Maharg, 'Learning from learning: the dialogue of virtual and real courts' at http://www.bileta.ac.uk/98papers/barton.html
} 


\section{Toulmin and Argument: Process and Product}

Recently, there has been an increasing interest in the extent to which logical models of argument can be employed in the modelling, teaching and learning of legal argumentation using IT. ${ }^{30}$ These encompass computational dialectics, ${ }^{31}$ dialectical models of argumentation, ${ }^{32}$ legal knowledge based systems (LKBS), ${ }^{33}$ and case-based reasoning. 34

Most of these approaches support Gordon's claim that 'models of this kind have enormous practical and theoretical utility', not only for the AI community but for jurists as well. Gordon went on to describe in general terms the 'purpose, object and claims' of a model, then went on to make an important statement regarding them:

Talking about the purpose, object and claims of the model is somewhat misleading, as these are not inherent properties of the model, but are better understood as a relationship between an agent and the model. Thus, when I speak of the purpose of a model, I really mean the purpose intended by some user of the model. ${ }^{35}$

Gordon goes to the heart of the issue here. A model is simply a representation of information in a specific structure, and claims for the model's effectiveness qua model can only arise from its use by particular agents in specific social or disciplinary circumstances. Indeed, unless the model is used or projected into an actual and useable environment, any description of its operation within the real world must be constrained

${ }^{30}$ A.R. Lodder and B. Verheij, 'Opportunities of Computer-Mediated legal Argumentation in Education', 12th Annual BILETA Conference, 'The Future of Legal Education and Practice',

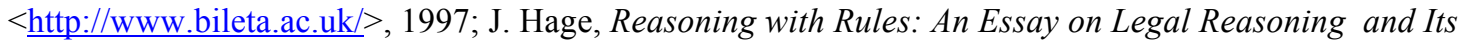
Underlying Logic, Kluwer Academic Publishers, Dordrecht, 1997; H. Prakken, Logical Tools for Modelling Legal Argument: A Study of Defeasible Reasoning in Law, Kluwer Academic Publishers, Dordrecht, 1997; H. Prakken and G. Sartor, 'A Dialectical Model of Assessing in Conflicting Arguments in Legal Reasoning' Artificial Intelligence and Law, vol 4, pp.331-368, 1996

${ }^{31}$ R. Kowalski and R. Toni, 'Abstract Argumentation' Artificial Intelligence and law, vol 4, pp.275-96, 1996; A.R. Lodder, and A. Herczog, 'DiaLaw - A Dialogical Framework for Modeling Legal Reasoning', Proceedings of the Fifth International Conference on Artificial Intelligence and Law, ACM, Boston, pp.146-155, 1995

${ }^{32}$ K.L. Branting, K.L., 'A Computational Model of Ratio Decidendi' Artificial Intelligence and Law, vol 2, pp.1-31, 1994; A.M. Farley and K. Freeman, 'Burden of Proof in Legal Argumentation', Proceedings of the Fifth International Conference on Artificial Intelligence and Law, Boston, ACM Press, pp.156-64, 1995

33 T.J.M. Bench-Capon, \& F.P. Coenen, 'Isomorphism and Legal Knowledge Based Systems' Artificial Intelligence and Law, vol 1, pp.65-86, 1992; T.J.M. Bench-Capon, 'Legal Theory and Legal KBS - A Computer Scientist's Perspective’ JURIX 1994, <http://jurix.bsk.utwente.nl/html/j94.htm>; C. Groendijk and M. Tragter, 'Statistical and Neural Approaches to Smart-Money Determination', JURIX 1995, $<$ http://jurix.bsk.utwente.nl/html/j95.html $>$

${ }^{34}$ V. Aleven, \& K.D. Ashley 'Evaluating a Learning Environment for Case-Based Argumentation Skills', Proceedings of the Sixth International Conference on Artificial Intelligence and Law, Boston, ACM Press, 1997, pp.170-79

${ }^{35}$ T.F. Gordon, The Pleadings Game - An Artificial Intelligence Model of Procedural Justice, Kluwer Academic Publishers, Dordrecht, 1995, 20 
by this lack of context. Gordon is thus right to propose for AI the role of 'modelling, not constructing, intelligence'. In doing so, he points to the interface between model and the world which is always implied when one talks of models and which cannot be elided by the model's designer.

Gordon's view is given support by Paliwala who, in his keynote address to the 1997 JURIX conference, observed that many of the unresolved issues surrounding AI and law can be best approached by 'a return to a cybernetic systems theory'. ${ }^{36}$ In particular, he argued, 'the relationship between the producers and the users needs to be reconceptualised through micro-analysis and anthropological observation'. ${ }^{37}$ Where Gordon comments upon the relationship between agent and model, Paliwala highlights the relationship between producers or designers and the user. Both are, in different ways, raising issues of intentionality and contextuality, while Paliwala quite deliberately sets these within an interdisciplinary context.

The importance of these two issues to the relationship of law and AI can be seen if we consider in more detail the use of a model by AI theorists, namely the Toulmin Dialogue Game (TDG), as developed by Bench-Capon and others. As Bench-Capon points out, this schema derives from the distinctively European development of interest in argumentbased, non-monotonic approaches to legal reasoning, and from the interest within this tradition in Stephen Toulmin's argument schema. ${ }^{38}$ The use and in some cases adaptation of Toulmin's work is at first glance a curious common denominator in these schema and implementations. Bench-Capon, however, gives a good account of its attractiveness for AI research in the rule-based tradition: ${ }^{39}$ it is a flexible and global model of argument procedure which, while rule-based, can accommodate qualification and rebuttal. As he states,

the point of the TDG is not so much to enforce logically correct behaviour as to ensure that the final argument, which emerges from the dialogue, has the structure prescribed by Toulmin. The result is a game with more varied moves which we believe, and hope to show, enables a more faithful modelling of the kinds of dialogues found in everyday discourse. Moreover, these additional elements are considered important for representing legal arguments. $^{40}$

\footnotetext{
${ }^{36}$ A. Paliwala, 'An Intellectual Celebration: 10 Years of JURIX Conferences', JURIX 1997a, $<$ http://jurix.bsk.utwente.nl/papers_pdf/j97-pdf/paliwala.pdf $>, 4$

${ }^{37}$ Ibid.

${ }^{38}$ See S. Toulmin, The Uses of Argument, Cambridge, Cambridge University Press, 1958. Bench-Capon cites examples of other uses of Toulmin's argument structures: C.C. Marshall, 'Representing the Structure of a Legal Argument' Proceedings of the Second International Conference on AI and Law, Vancouver, ACM Press, 121-127, 1989; L.S. Lutomski, 'The Design of an Attorney's statistical Consultant' Proceedings of the Second International Conference on AI and Law, Vancouver, ACM Press, 224-33, 1989; G. Storrs, 'The Policy System', Knowledge Based Systems and Legal Applications, T.J.M. BenchCapon (ed) London, Academic Press, 165-82, 1991; J. Zeleznikow and A. Stranieri, 'The Split-up System: Integrating Neural Nets and Rule Based Reasoning in the Legal Domain', Proceedings of the Fifth JURIX International Conference on AI and Law, 185-94, 1995. See T.J.M. Bench-Capon, 'Argument in Artificial Intelligence and Law', JURIX 1995, < http://jurix.bsk.utwente.nl/html/j95.html>, 8.

${ }^{39}$ See Bench-Capon 1995, 9

${ }^{40}$ T.J.M. Bench-Capon, 'Specification and Implementation of Toulmin Dialogue Game', JURIX 1998,
} 
Toulmin would thus seem to provide Bench-Capon and others with an instrument, which can organise argument and generate the type of legal defeasibility acceptable to lawyers, logicians and the AI community -- the three audiences addressed by Bench-Capon and his peers.

However, there are two assumptions made by the above description of the TDG. First there is the presumption that Toulmin's structures as amended by Bench-Capon model (in Gordon's sense) the reality of legal argumentation. Secondly (and in spite of BenchCapon's emphasis on the co-operative nature of the game) there is curiously little agency, intentionality or context in this description. Who is the game for, and who will play it? In which social or legal context will it be used? If social context is essential to law's performative nature, which context and which audience are envisaged? These are important criteria, which affect a user's manipulation of the model in legal practice. Hart, for instance, concluded from his research into use of Toulmin's model that 'the amount of commonality a speaker perceives [with the audience] will affect the claims he makes, the data he offers, and the warrants he provides'. ${ }^{41}$ He also discovered 'pronounced differences in the numbers of warrants explicitly supplied by speakers facing committed audiences and those facing collective distrust or disagreement'. ${ }^{4}$

It might be argued in response to this that Hart's analyses of Toulmin in action actually serve to reinforce the model's application to law, for they prove its usefulness as a flexible description of the varieties of legal argument which, given sophisticated interfaces, could easily match audience and user expectation. This is undeniable; but so too is the point that there is much more to legal argumentation than a reduction of it to a set of formal characteristics. Toulmin may have given us a generic description of argument, which can be applied to the product of legal argumentation; but does it describe the process by which expert lawyers dispute? ${ }^{43}$ Moreover, despite its promise of apparent dialogism, there is arguably little room in the Toulmin model for the rhetoric of law as enacted in documents or in courts. There are many examples from sociolegal literature we can take to illustrate the point. Commentators, for example, have argued the importance of the complexities of gender differences and relational contexts in legal discourse. ${ }^{44}$ If we were to look for a meta-description of the approach taken by these

$<$ http://jurix.bsk.utwente.nl/html/j98.html $>, 1$.

${ }^{41}$ R.P. Hart, 'On Applying Toulmin: The Analysis of Practical Discourse', Explorations in Rhetorical Criticism, G.P. Mohrmann, S.J. Stewart and D. Ochs (eds)., University Park, Pennsylvania State University Press, 75-95, 1973, 83

${ }^{42}$ Ibid., p.84. These passages are cited in R. Fulkerson, 'The Toulmin Model of Argument and the Teaching of Composition', Argument Revisited: Argument Redefined. Negotiation Meaning in the Composition Classroom, B. Emmel, P. Resch and D. Tenney (eds), Thousand Oaks, CA, Sage Publications 45-72, 1996, 69

${ }^{43}$ Fulkerson raised the same point when he stated that 'Toulmin's model has been found useful as an analytical tool but problematic as a means of generating arguments, and the gulf between describing finished texts and teaching students to produce them is wide.' Ibid., 51

${ }^{44} \mathrm{H}$. Giles, and N. Coupland, Language: Contexts and Consequences, Pacific Grove, California: Brooks/Cole Publishing Co, 1991; J.M. Conley, John M. and W.M. O’Barr, Just Words: Law, Language, and Power, Chicago: University of Chicago Press, 1998; H. Jacob, 'The Elusive Shadow of the Law', 26 Law and Society Review 565-90, 1992; S.E. Merry, Getting Justice and Getting Even: Legal Consciousness Among Working Class Americans, Chicago: University of Chicago Press, 1990 
rhetorical initiatives, we might find it in James Boyd White's comprehensive description of law's performative nature. For him, law is always culture specific; and its rhetoric constitutive of the language and formal tropes it employs' ${ }^{45}$ Its rhetoric is also constitutive of identities:

[t]his means that the rhetorician - that is, each of us when we speak to persuade or to establish community in other ways - must accept the couble fact that there are real and important differences between cultures and that one is in substantial part the product of one's own culture. The rhetorician, like the lawyer, is thus engaged in a process of meaning-making and community-building of which he or she is in part the subject. ${ }^{46}$

The ability of such argument to create and define a professional group and its practice is critical to the nature of legal argument. Indeed it is central to law's portrayal of itself as a discipline with a formal existence in that it covers its rhetorical tracks so as to establish its presence in the domains of logic, objectivity, and reason. ${ }^{47}$

If we consider Toulmin's model in the light of White's characterisation of law as rhetoric, the two representations of law would appear to be antithetical. Toulmin's model is designed to transcend local practices; cultural resources specificities are difficult to categorise in the model; the relations between identity, ethics and language lie outwith the model altogether. The model was in fact designed to be descriptive only, and descriptive of the structure of argument, as we shall see below. For this reason alone, it is highly doubtful whether its structure of claim, data, warrant, backing can encompass the rhetorical nature of law in practice. $^{48}$

Whether Toulmin's model can be used effectively in education is another matter. It is interesting that Bench-Capon advocates its usefulness in the teaching and learning of legal argument, stating that 'Toulmin's schema provides a particularly promising starting point for us, since it is widely used on courses, which teach argument skills'. ${ }^{9}$ Once again, we require to take an interdisciplinary perspective on this statement. The model has indeed been widely used, in both courses and texts, but its usefulness is the subject of considerable debate.

The claims for the use of the Toulmin model within education have been examined by a number of commentators. One of the more recent and least partisan has been Fulkerson, who surveys the use of Toulmin's model and its educational effectiveness within

\footnotetext{
45 'Law as Rhetoric', p.690 GET FULL REFERENCE

${ }^{46}$ James Boyd White, Heracles' Bow, Madison: University of Wisconsin, 1985, pp.39-40

${ }^{47}$ See for example, S. Fish, op.cit. It is interesting to note that White's view is paralleled in some respects by some of the contemporary literature on compositional skills. Lea and Street for instance, have categorised what they call the 'Academic Literacies' approach to writing, where literacy is defined not as student deficit, or study skills or acculturation into academic discourse, but as 'social practices at the level of epistemology and identity'. See M. Lea and B. Street, 'Student writing in higher education: an academic literacies approach', Studies in Higher Education, June 1998, 83

${ }^{48}$ It is interesting to note that Toulmin's book provoked hostility in his philosophical circle, for it was held that he had relinquished the strait path of formal logic for 'antilogic'. See Fulkerson 1996, op.cit., 45-6.

${ }^{49}$ T.J.M. Bench-Capon, 'A Computer Supported Environment for the Teaching of Legal Argument', $13^{\text {th }}$ annual BILETA Conference, 'The Changing Jurisdiction', 1998, 2
} 
classrooms (predominantly in composition and argument classes: he does not deal with AI uses of the model). As Fulkerson points out, Toulmin's model was adopted quite early after its initial publication in the UK, in American schools as a new approach to argument in the context of composition and rhetoric. Toulmin himself noted the irony of this: More than thirty years ago, when I sat down to write my book, The Uses of Argument, the last thing I had in mind was to revive the theory of rhetoric. My own concern with 'substantive inferences' sprang directly from my dissatisfaction with the current state of the theory of knowledge, and my target was other philosophers ... Only when I came to understand the reason why the American speech communication and forensic communities took the book so seriously could I even (so to say) grasp the significance of my own work! $!^{50}$

But if the model now has acquired a lineage in the history of philosophy and rhetoric, Fulkerson is right when he remarks that it is no longer canonical within the rhetorical tradition: [it] is becoming more, not less, controversial, albeit on different terms than those of philosophy's debate within it'. ${ }^{51}$ Commenting on the results of the research on Toulmin as well as his own experience of using it to teach argument, he notes four problems in applying Toulmin to major argument structures:

1. use of the model in the classroom requires 'extensive analysis, patience and a lot of practice'

2. application of the model at discourse level is "not a routine or algorithmic procedure in which various analysts would produce the same layout'

3. the model 'fails to assist in making value judgements' regarding the quality of argument within a discipline or professional domain. (This criticism is one with which Toulmin may well agree, since he has elsewhere described the quality of argument as being essentially field-dependent.

4. some 'traditional principles of argument evaluation' are not accounted for by Toulmin's model ${ }^{52}$

Fulkerson goes on to summarise research into use of Toulmin within a variety of domains, citing van Eemeren, Grootendorst and Kruiger, and Hart, amongst others. ${ }^{53}$ According to him, it is by no means clear that the Toulmin model brings significant benefits to the teaching and learning of argumentation: at present we have a 'good deal of lore about the Toulmin model', together with 'theorising and philosophising. What we

\footnotetext{
${ }^{50}$ Cited in Fulkerson, 1996 op.cit., 46. See also R. Fulkerson, 'Some Uses and Limitations of the Toulmin Method of Argumentation', The Toulmin Method: Exploration and Controversy, Arlington, TX: Liberal Arts, 80-95, 1991. The cross-over from one discipline to another implied in Toulmin's statement here is a classic instance of interdisciplinary research and appropriation. Paul Ricoeur describes it well: 'To understand an author better than he understood himself is to unfold the revelatory power implicit in his discourse, beyond the limited horizon of his own existential discourse'. P. Ricoeur, Hermeneutics and the Human Sciences: Essays on Language, Action and Interpretation, edited, translated by John B. Thompson, Cambridge University Press, 1981, 191

${ }^{51}$ Ibid.

${ }^{52}$ Ibid., 55-6; 48

${ }^{53}$ F.H. van Eemeren,. R. Grootendorst, T. Kruiger, 'Toulmin's Analysis Model', Handbook of Argumentation Theory: A Critical Survey of Classical Backgrounds and Modern Studies, Dordrecht, Holland/Providence, RI, Foris, 162-207, 1987; Hart, op.cit. See also A.H. Fairbanks, 'The Pedagogical Failure of Toulmin's Logic' The Writing Instructor 12 (Spring/Summer) 103-14, 1993
} 
need is further careful research (including experiments, ethnographies, and case studies) ${ }^{54}$ Much the same could be said of a more recent article by Chinn and Anderson which attempts to use an amended Toulmin model to stimulate interactive reasoning in collaborative reasoning discussions. ${ }^{55}$ The article presents much theory about Toulmin and argumentation in the classroom, but offers little research evidence, either qualitative or quantitative, that such use of the model stimulates more effective formation of argument among students.

Fulkerson is talking here about the use of Toulmin in the domain of composition research, but the same could probably be said for AI adaptations of Toulmin, too. The same four problems that Fulkerson raises concerning the use of Toulmin in composition classes could be said to be applicable to AI adaptations. As Fulkerson points out, this research is crucial, for Toulmin's original model was not designed as a classroom heuristic: the model is descriptive, not generative, of argument. Indeed Toulmin himself took a remarkably situationist approach to the learning of argument, commenting that it is learned through apprenticeship in specific fields. ${ }^{56}$

In many respects the reception of Toulmin by other disciplines is a cautionary tale for interdisciplinary studies. It is interesting that of the problems identified with Toulmin's model above, only number four is a criticism of Toulmin per se. The other points deal with the ways the model was used by others in their own fields. What it reveals is the extent to which the catenation of ideas by which knowledge proceeds in any specific discipline require to be carefully examined before one of the concepts is prised out and used for other purposes. It is by no means certain that the seductive simplicity of Toulmin's model in its descriptive context transfers easily, if it does at all, to other more applied and generative contexts.

At this point, the reader might be forgiven for thinking that in issuing such a caution, I am arguing against interdisciplinary practice. On the contrary: it is only by a more thoroughgoing interest in disciplinary practices and arguments that we can use interdisciplinary endeavour to enrich our own domain. This has been recognised for some time in other disciplines, and often surfaces at times when disciplines question the nature of their own identity. In education, for example, there was one such thread of debate in the late sixties in the US. Joseph Schwab argued against the wholesale importation of theories into the practice of education and the use of concepts derived from them as principles of learning. ${ }^{57}$ Yet he also acknowledged the synthetic nature of education as a discipline, and consequently took the view that no single theory would ever supply an adequate basis for educational practice. Instead, he advocated what he termed 'polyfocal conspectus' -- an interdisciplinary merging of theory from multiple

\footnotetext{
${ }^{54}$ Op.cit, 68

${ }^{55}$ C.A. Chinn and R. D. Anderson, 'The Structure of Discussions Intended to Promote Reasoning', Teachers College Record, 100, 2, 315-68, 1998

${ }^{56}$ S. Toulmin, 'Logic and the Criticism of Arguments', The Rhetoric of Western Thought, fourth edition, J.L. Golden, G.F. Berquist, W. Coleman, (eds), Dubuque, IA, Kendall/Hunt, 374-88, 1989, 378, cited in Fulkerson, 1996, op.cit., 63

${ }^{57}$ J.J. Schwab, The Practical: A Language for Curriculum Washington DC, National Educational Association, 1970
} 
sources with the grounding experience of teachers and learners. Paliwala has argued for something similar in the relationship between AI and law: 'AI work is better conceived in terms of a cybernetic partnership between computers and human programmers, domain experts and users' ${ }^{58}$ Nor is this notion foreign to law. Jurisprudence, perhaps the most synthetic of law's domains, has undergone its postmodern crises; and legal education, what we might call an emerging sub-domain with all the growing pains that that entails, is a highly porous region, drawing upon psychology, education, and many other areas of knowledge.

It is in this respect that the title of this paper is significant. Normally, the use of one disciplinary concept in another discipline is accompanied by metaphors of borrowing, taking, displacement; of borders, boundaries and maps. ${ }^{59}$ Interdisciplinary researchers 'cross' such borders, have a 'home' discipline, 'borrow' concepts in other domains, and the like. The Scots word 'reiving', in many of its meanings, expresses this well: the sense of raiding across borders, carrying off, the violent intrusion into other communities. But there is another sense of the word, which makes it profoundly descriptive of the nexus of law, legal education, IT, AI, compositional studies, rhetoric and the other disciplines cited in this paper. In the late sixteenth century, the word came to have the meaning of 'to rescue ... by carrying off' (my emphasis). ${ }^{60}$ Law's use of IT in legal practice and education requires us to rescue concepts which have become possessed by other disciplines, other tribes within the recent history of university specialisation, but which were really always part of law's project. Law needs to re-acquire the sense of the rhetorical, and of social context in IT use; and an awareness of the necessity of interpreting relevant lines of research in disciplines adjacent to its own concerns. On p.5 above I argued that educational interventions into argument and writing require integrative strategies underpinned by researched and appropriate educational theory (perhaps I should have written 'appropriated' theory). I would argue that the same applies to AI models of argumentation, which would surely become more robust if both lawyers and AI practitioners in this field considered not only the social context of their models, but also the rhetorical and educational research applicable to their models.

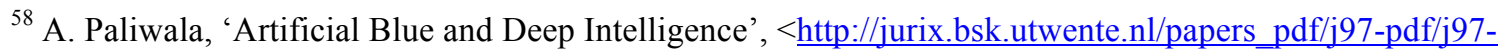
8.pdf>, 1997, 104

${ }^{59}$ See G. Squires, 'Interdisciplinarity in Higher Education in the United Kingdom', European Journal of Education, 27, 201-9, 1992; Tony Becher, (1989) Academic Tribes and Territories, Milton Keynes, Open University Press, 1989; Tony Becher, 'The Significance of Disciplinary Differences' Studies in Higher

Education, 19, 151-61, 1994; Tony Becher, 'The Learning Professions', Studies in Higher Education, 21 , 43-55, 1996

${ }^{60}$ The Concise Scots Dictionary (1985), editor-in-chief Mairi Robinson, Aberdeen University Press
} 